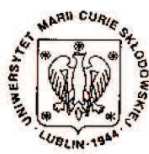

Annales UMCS Informatica AI XIV, 3 (2014) 15-20 DOI: $10.2478 /$ umcsinfo-2014-0018

Annales UMCS

Informatica

Lublin-Polonia

Sectio AI

http://www.annales.umcs.lublin.pl/

\title{
Synchronous SSVEP Data Acquisition System
}

\author{
Sławomir Kotyra ${ }^{1 *}$, Grzegorz M. Wójcik ${ }^{1 \dagger}$, Marcin Smolira ${ }^{1 \ddagger}$ \\ ${ }^{1}$ Institute of Computer Science, Maria Curie-Sklodowska University, \\ Akademicka 9, 20-033 Lublin, Poland
}

\begin{abstract}
Steady State Visually Evoked Potentials have been known for several decades and they appear in the primary visual cortex of brain as a result of light stimulation of the sense of sight. In this article a simple method for electroencephalographic data acquisition is presented. The system is based on the DSM-51 unit connected to goggles with blinking diodes and Mindset-1000 EEG amplifier with 16 channels. We present self-developed hardware and method of effective synchronization for the light stimulation and brain activity recording.
\end{abstract}

\section{Introduction}

The phenomenon of signals of electrical nature evoked in the nervous system through the stimulation of the sense of sight by light was already observed towards the end of the nineteenth century $[\mathbf{1}, \mathbf{2}]$. A special case of this phenomenon is the stimulation of the retina by a monotonously modulated light stimulus. It is known as the Steady State Visually Evoked Potentials (SSVEP).

While examining this phenomenon it is critical to precisely synchronize the stimulus and the analyzed EEG signal $[\mathbf{3}]$. Without this condition, it is much more difficult, if not impossible, to obtain credible results.

Good understanding of the engineering and mechanisms of communication taking place in different brain regions is crucial for development of reliable brain-computer interface $[4,5,6,7,8,9]$.

*slawomir.kotyra@umcs.lublin.pl

†'gmwojcik@gmail.com

${ }^{\ddagger}$ marcin.smolira@gmail.com 


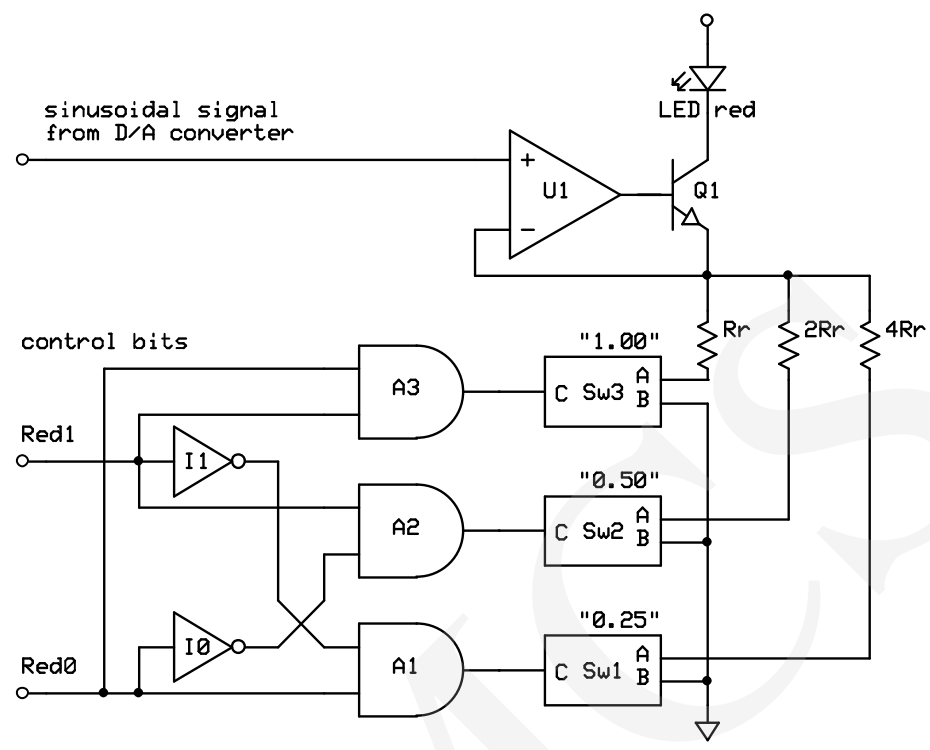

Fig. 1. Part of adapter controlling RED component

\section{Materials}

In the solution described below, a DSM51 microprocessor system was used as a driver working in hard real-time mode. This mode provides precise timing, and is possible after the capture of timer interruption.

The DSM51 system contains the three eight-bit digital I/O ports, and an eight-bit digital-to-analog (DAC) converter [10].

During the direct stimulation of the sense of sight, a specially designed pair of goggles with tri-color (RGB) LEDs were used.

A specially designed adapter provides the transformation of the control signals coming from the DSM51 into the currents controlling the RGB LEDs embedded in the goggles. Fig. 1 shows the one-third of the adapter which is responsible for the control of the brightness of the red component.

The EEG signal was acquired by means of a Mindset 1000 amplifier (Nolan Computer Systems production). It is a 16-channel device with 16-bit analog-to-digital converter and a software-programmable sampling rate of $64,128,256,512$ or 1024 samples per second from each channel [11].

Fig. 2 shows a diagram illustrating the idea of a SSVEP research set action [12].

The data acquisition system, as used here, has been described in $[\mathbf{1 3}, \mathbf{1 4}]$. 


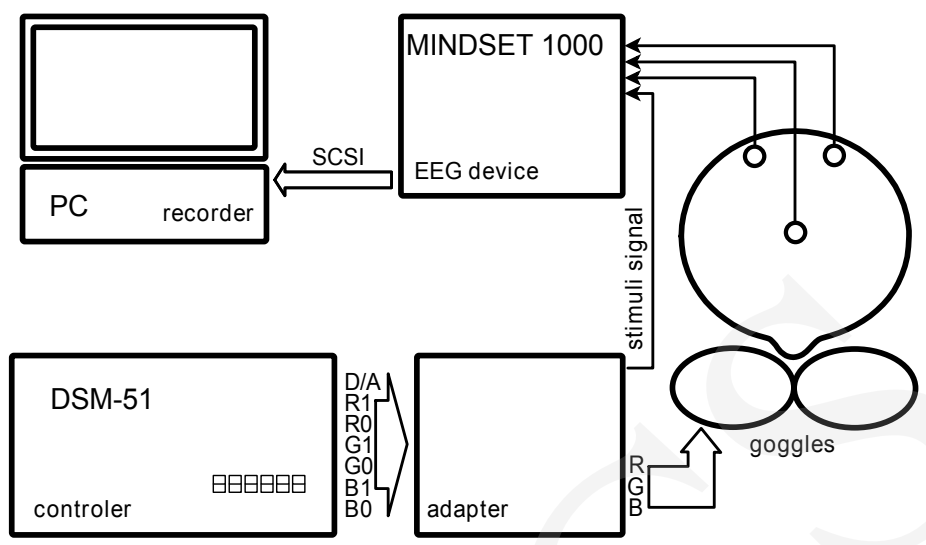

Fig. 2. SSVEP research set

\section{Methods}

The brightness of RGB LEDs embedded in the goggles was modulated by a sinusoidal signal coming from the digital-to-analog DSM51 converter. 28 frequencies between 3 and $30 \mathrm{~Hz}$ in steps of $1 \mathrm{~Hz}$ were used. The period of modulation for each frequency was 1 second.

The reason behind the use of a sinusoidal signal is that it reduces the harmonic content in the signal evoked.

In addition to the sinusoidal modulation of light intensity for each RGB component, it is possible to determine one of the four levels of brightness: $100 \%, 50 \%, 25 \%$ and $0 \%$. This depends on the value of two bits of parallel I/O port of the DSM51. For the three RGB colours, 6 bits in total were used. (see Figs 1 and 2).

It was assumed that at least one RGB component is emitted with $100 \%$ intensity. In this way, it was possible to create 37 different colours. These colours are presented in Table ?? as hex strings known from HTML.

Taking into account the periods of goggles extinction, the duration of the entire experiment can be roughly estimated as $(29 \cdot 38=1102)$ seconds, which is more than 18 minutes.

Thanks to the high-precision timing of the DSM51 system, the error of time for the entire study did not exceed $2 \mathrm{~ms}$, which was negligibly small.

The EEG device took 256 samples of signal per second.

The EEG signal was acquired through two electrodes named O1 and O2 in the 10/20 system. The function of the reference electrode was performed by the electrode $\mathrm{Cz}$.

\section{Solution}

To ensure a synchronous recording of the stimulating signal and the EEG signal containing the evoked reaction, a specially prepared (amplitude-limited) sinusoidal 


\begin{tabular}{|c|c|c|}
\hline \multicolumn{3}{|c|}{ FFFFFF } \\
\hline FFFF7F & FFFF3F & FFFF00 \\
\hline FF7F7F & FF7F3F & FF7F00 \\
\hline FF3F7F & FF3F3F & FF3F00 \\
\hline FF007F & FF003F & FF0000 \\
\hline 7FFFFF & 3FFFFF & 00FFFF \\
\hline 7FFF7F & 3FFF7F & 00FF7F \\
\hline 7FFF3F & 3FFF3F & 00FF3F \\
\hline 7FFF00 & 3FFF00 & 00FF00 \\
\hline FF7FFF & FF3FFF & FF00FF \\
\hline 7F7FFF & 7F3FFF & 7F00FF \\
\hline 3F7FFF & 3F3FFF & 3F00FF \\
\hline 007FFF & 003FFF & 9090FF \\
\hline
\end{tabular}

Table 1. Stimulation colors

signal modulating the brightness of RGB LED light - that is a stimulatory signal was introduced at the input of one of the MS1000 amplifier channels. This is very important because the collected signal is then subjected to a multistage processing, which includes, inter alia, digital filters limiting the frequency band to the range of interest. Each stage of signal processing can cause a delay between the source signal and the resulting signal.

In the described solution, the adapter mentioned above also suppresses the signal driving the RGB LEDs in the goggles to a level which enables the EEG amplifier to record it. To ensure compliance with the medical standards, the synchronizing signal fed from the adapter to the EEG device must be electrically isolated, for example by means of a transformer or an optoelectronic element (see Fig. 2).

\section{Summary}

In the proposed method the stimulatory signal goes the same way as the EEG signal, so there is no accumulation of time errors that may arise during the processing of the signal. 
Such approach provides a sound basis for further correct analysis of the effectiveness of the stimulation, which is particularly important if the signal is to be processed in real time - for example in the studies of neurofeedback phenomena.

\section{Future Plans}

The system described in this paper provides a very good basis for an integrated research environment. It contains a platform for the management of the collected data and an application for the remote preparation and management of the experiment.

Thanks to this solution, the system operator and the person tested will not have to stay in the same room during the experiment. At the same time, full control over the test will be secured. Another advantage of this solution is the possibility of recording the obtained measurement data in a properly-designed database. The basis for such an integrated system can be the Raspberry PI platform.

The advantage of this solution are the small sizes and the variety of available connectors such as HDMI, CSI - Camera Serial Interface DSI - Display Serial Interface, AudioJack, GPIO-General Purpose Input / Output, plug the SD card, USB, Ethernet. Extensive documentation on the manufacturer's website and the six Linux distributions created specifically to work with the Raspberry PI microcomputer, help to adapt the platform to one's needs.

\section{Acknowledgments}

This paper is part-financed by The European Social Fund.
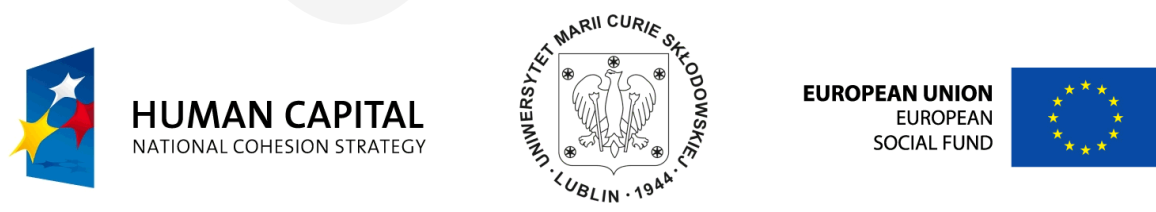

\section{References}

[1] Beck A., Über die Belichtigung der Netzhaut von Eledone moschata entstandenen Actionströme, Arcg gs Physiol 78 (1899).

[2] Beck A., O zjawiskach elektrycznych wywołanych przez oświetlenie siatkówki głowonoga Eledone moschata, Kosmos 25 (1900).

[3] Cecotti H., Volosyak I., Graser A., Reliable visual stimuli on LCD screens for SSVEP based BCI, The 2010 European Signal Processing Conference (EUSIPCO-2010), Aalborg: Danemark (2010).

[4] Tadeusiewicz R., The Industrial Electronics Handbook - Intelligent Systems by B.M. Wilamowski, J.D. Irvin (eds.), chapter Introduction to Intelligent Systems, CRC Press, Boca Raton (2011): 1.1 . 
Pobrane z czasopisma Annales AI- Informatica http://ai.annales.umcs.pl

Data: 26/04/2023 15:21:56

[5] Tadeusiewicz R., New Trends in Neurocybernetics, Computer Methods in Materials Science 10(1) (2010): 1 .

[6] Tadeusiewicz R., Inżynieria Biomedyczna, chapter Modele systemów biologicznych i ich zastosowania, Kraków UWND (2008): 191.

[7] Tadeusiewicz R., Problemy Biocybernetyki i Inżynierii Biomedycznej, Tom 5, chapter Cybernetyczne modelowanie fragmentów systemu nerwowego zaangażowanych w procesie sterowania ruchem, Wydawnictwa Komunikacji i Łączności, Warszawa (1990): 125.

[8] Mikołajewska E., Mikołajewski D., Neuroprostheses for increasing disabled patients' mobility and control, Advances in Clinical and Experimental Medicine 21(1) (2012): 263.

[9] Mikołajewska E., Mikołajewski D., Exoskeletons in neurological diseases - current and potential future applications, Advances in Clinical and Experimental Medicine 20(2) (2011): 227.

[10] Gałka P., DSM-51 Dydaktyczny System Mikroprocesorowy Instrukcja Obsługi, MicroMade Gałka i Drożdż sp. j. (2005).

[11] Nolan W., MindSet MS1000 Hardware Reference Manual, Nolan Computer Systems (2000).

[12] Kotyra S., Method and research equipment for synchronous SSVEP signal recording, In Acta Neurobiol Exp, Lublin: Poland, June 2014, IX Konferencja "Techniki elektrofizjologiczne" 74 (3) (2014).

[13] Kotyra S., Wójcik G. M., Developing brain electric activity acquisition software for Linux, Ann. UMCS, Inf. 10(1) (2010): 7.

[14] Kotyra S., Wójcik G. M., The System of Electric Brain Activity Acquisition from EEG Equipment for Linux OS, Ann. UMCS, Inf. 8(1) (2008): 151. 